\title{
Simulasi Pembelajaran Internet of Things menggunakan Cisco Packet Tracer 7.1.1
}

\author{
Zaeni Miftah \\ STMIK Eresha \\ zaenimiftahə2@gmail.com
}

\begin{abstract}
Abstrak- Perkembangan teknologi informatika saat ini sangat membantu bagi kehidupan manusia, terutama teknologi yang dikenal dengan Internet of Things (IoT) dimana teknologi ini dikenal mampu menghubungkan semua perangkat elektronika dengan kontroller yang dikendalikan melalui jaringan internet, seperti contoh gerbang atau garasi otomatis dimana proses kerja yaitu inputan berupa sensor kemudian diproses melalui mikrokontroller unit dan output dapat menggerakkan garasi rumah dan masih banyak lagi manfaat dari teknologi ini. Dalam membangun sebuah teknologi Internet of Things maka diperlukan pengetahuan dasar jaringan komputer yaitu protokol TCP/IP dan bahasa pemrograman, untuk bahasa pemrograman disini dapat menggunakan bahasa pemrograman seperti arduino serta beberapa perangkat keras yang diperlukan seperti microcontroller unit (MCU), Sensor dan Aktuator sedangkan perangkat lunak disini seperti editor Arduino IDE. Kebutuhan sarana dan prasarana ini tentunya membutuhkan biaya yang tidak sedikit, bagi beberapa kalangan dalam memenuhi kebutuhan seperti perangkat keras ataupun perangkat lunak untuk pembelajaran internet of things ini masih menjadi masalah, dengan menggunakan software simulai seperti software Cisco Packet Tracer yang digunakan sebagai simulasi pembelajaran Internet of Things sehingga masalah keterbatasan dari perangkat keras ataupun perangkat lunak dapat teratasi. dalam pembelajaran ini perangkat yang dirancang yaitu pintu garasi mobil dapat dibuka menggunakan Smartphone atau Tablet-PC dan sensor gerak digunakan untuk mendeteksi adanya objek yang bergerak kemudian sinyal diteruskan ke MCU selanjutnya menyalakan alaram, lampu LED dan Speaker.
\end{abstract}

Kata Kunci- IoT, Simulasi, Protokol TCP/IP, MCU, Cisco Packet Tracer, Sensor, Aktuator.

\section{Pendahuluan}

Perkembangan teknologi informatika saat ini sangat membantu bagi kehidupan manusia, terutama teknologi yang dikenal dengan Internet of Things (IoT) dimana teknologi ini dikenal mampu menghubungkan semua perangkat elektronika dengan kontroller yang dikendalikan melalui jaringan internet, seperti contoh gerbang atau garasi otomatis dimana proses kerja yaitu inputan berupa sensor kemudian diproses melalui mikrokontroller unit dan output dapat menggerakkan garasi rumah dan masih banyak lagi manfaat dari teknologi IoT ini. Dalam membangun sebuah teknologi Internet of Things maka diperlukan pengetahuan dasar jaringan komputer yaitu protokol TCP/IP dan bahasa pemrograman.

Pada jaringan komputer diperlukan pemahaman terhadap protokol TCP/IP (Transmission Control Protocol/Internet Protocol) yaitu standar komunikasi data yang digunakan untuk tukar-menukar data dari satu peangkat ke perangkat lain dimana masing-masing perangkat diberikan alamat unik yang dikenal dengan ip address pada jaringan Internet.

Pada bahasa pemrograman disini disesuaikan dengan board mikrokontroller yang digunakan karena board yang digunakan menggunakan Arduino Uno maka dapat menggunakan bahasa pemrograman arduino sedangkan editor dapat menggunakan Arduino IDE.

Pada perangkat keras yang diperlukan seperti mikrokontroller unit (MCU), Sensor dan Aktuator, pada perkembangannya untuk pembelajaran teknologi Internet of Things ini membutuhkan perangkat keras seperti pada bagian atau media inputan yaitu sensor jarak, sensor gerak, sensor temperatur, sensor gas, sensor cahaya, sensor suara. Pada bagian proses diperlukan mikrokontroller unit atau dikenal dengan (MCU) sedangkan pada bagian output dapat mengendalikan aktuator seperti motor penggerak, lampu atau cahaya, alaram atau penguat suara, penggerak hidrolik atau penumatik dan lain-lain. Kebutuhan sarana dan prasarana yang diperlukan untuk pembelajaran Internet of Things ini tentunya membutuhkan biaya yang tidak sedikit, bagi beberapa kalangan dalam memenuhi kebutuhan seperti perangkat keras ataupun perangkat lunak untuk pembelajaran internet of things ini masih menjadi masalah.

Dalam penelitian ini diperlukan sofware emulator untuk mengatasi masalah keterbatasan perangkat keras maupun perangkat lunak sehingga pembelajaran Internet of Things dapat terus berlangsung secara virtual, software yang digunakan yaitu Cisco Packet Tracer 7.1.

\section{KAJIAN PUSTAKA}

\section{A. Internet of Things (IoT)}

Internet of Things Istilah "Internet of Things" (IoT) pertama kali digunakan pada tahun 1999 oleh pelopor teknologi Inggris Kevin Ashton yang menggambarkan sebuah sistem di mana benda-benda di dunia fisik dapat dihubungkan ke Internet oleh sensor. Tujuan IoT adalah memungkinkan semua objek dapat terhubung Kapan saja, dimana saja melalui jaringan Internet.

Menurut beberapa peniliti tentang Internet of Things (IoT) saat ini teknologi Internet of Things sudah banyak diterapkan di beberapa bidang keilmuan dan industri, seperti dalam bidang ilmu kesehatan, pendidikan, komunikasi, 
bisnis, sains, pemerintah, kemanusiaan, informatika, geografis dan beberapa bidang ilmu lain.

Berdasarkan sumber dari Cisco IBSG bahwa Pada tahun 2003, ada sekitar 6,3 miliar penduduk bumi dan 500 juta perangkat terhubung ke Internet sedangkan pada tahun 2010, populasi manusia didunia meningkat menjadi 6,8 miliar sedangkan Pertumbuhan yang cukup signifikan yaitu perangkat smartphone dan PC tablet yang terhubung ke Internet hingga 12,5 miliar Cisco IBSG memprediksi akan ada 25 miliar perangkat yang terhubung ke Internet pada 2015 dan 50 miliar pada 2020.

\section{B. Simulasi}

Simulasi menurut kamus besar bahasa Indonesia adalah metode pelatihan yang meragakan sesuatu dalam bentuk tiruan yang mirip dengan keadaan yang sesungguhnya, Softaware simulasi adalah sebuah program yang memungkinkan pengguna untuk merancang serta mengamati proses pelatihan yang meragakan melalui simulasi tanpa benar-benar melakukan proses tersebut. Sofware simulasi digunakan secara luas dalam merancang peralatan sehingga hasil atau produk akhir akan sedekat mungkin dengan spesifikasi desain tanpa harus membeli perangkat yang mahal dan takut terjadinya kerusakan.

Software simulasi dapat membantu siswa untuk memahami berbagai disiplin ilmu secara konseptual hal ini dikarenakan siswa tidak memiliki rasa takut terhadap kegagalan, kerusakan ataupun kehancuran terhadap ilmu pengetahuan tersebut, sehingga pelajar dapat meningkatkan pemahaman dari konsep serta dapat dipertanggung jawabkan secara ilmiah.

\section{Protokol TCP/IP}

Protokol TCP/IP merupakan standard komunikasi dalam sebuah jaringan dimana protocol ini menggunakan skema pengalamatan yaitu IP Address dan FQDN.

IP Address merupakan model pengalamatan logis yang terdiri dari 32 bit masing-masing dipisahkan oleh tanda titik (.) yang ditulis dengan format AAA.BBB.CCC.DDD. IP Address dibagi menjadi dua yaitu Network_ID yang digunakan untuk mengidentifikasi jaringan lokal dan Host_ID digunakan untuk mengidentifikasi alamat host pada jaringan dan ini ditentukan berdasarkan nilai subnetmask yang diberikan kepada IP Adreess.

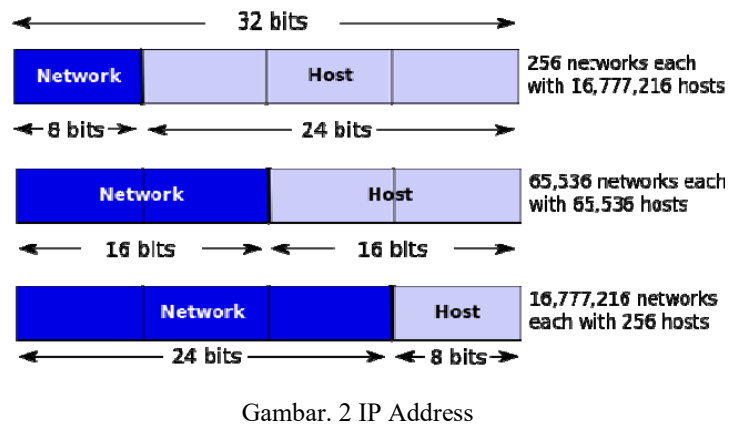

Fully Qualified Domain Name (FQDN): Alamat ini adalah alamat yang direpresentasikan menggunakan nama yang diekspresikan dalam bentuk <nama_host $>$.<nama_domain $>$, di mana $<$ nama_domain $>$ mengindentifikasikan jaringan dari lokasi sebuah komputer berada, dan <nama_host> mengidentifikasikan nama sebuah komputer pada jaringan. Pengalamatan FQDN digunakan oleh skema penamaan domain Domain Name System (DNS).

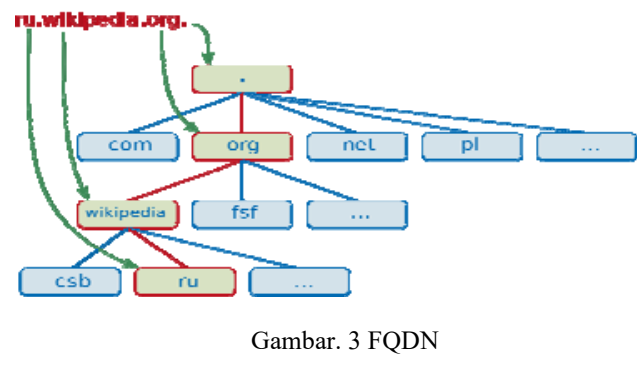

\section{Microcontroller Unit (MCU)}

Mikrokontroler unit adalah papan rangkaian elektronika yang dilengkapi dengan komponen dan chip yang berfungsi sebagai pengontrol rangkaian elektrik dan elektronika, umunya dapat menyimpan program, ada banyak macam microcontroller yang dapat digunakan untuk pembelajaran Inernet of Things salah satunya adalah Arduino Uno

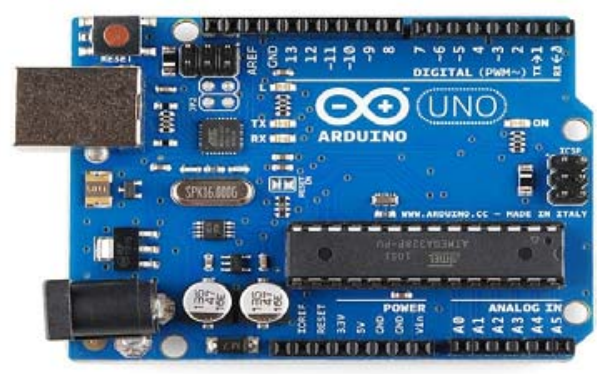

Gambar. 4 Board Arduino

\section{E. Cisco Packet Tracer}

Cisco Packet Tracer adalah salah satu aplikasi yang dibuat oleh perusahaan Cisco yang berlokasi di San Francisco, California didirikan pada tahun 1984. Cisco Packet Tracer sebagai alat simulasi yang digunakan dalam pembelajaran jaringan komputer dan IoT. Dalam software ini telah tersedia beberapa alat-alat yang sering dipakai atau digunakan dalam merancang suatu sistem jaringan dan IoT, Pada Gambar berikut dapat dilihat tampilan awal Cisco Packet Tracer

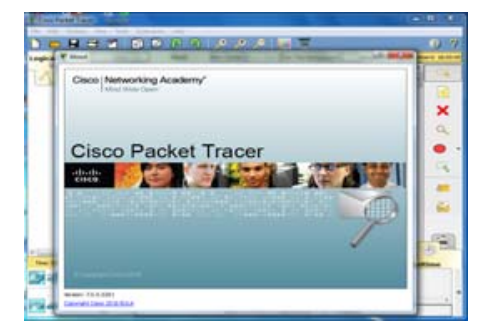




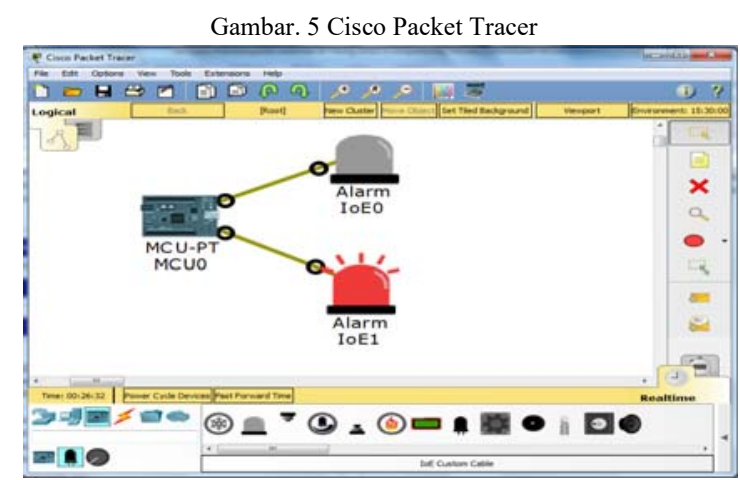

Gambar. 6 Simualasi IoT pada Cisco Packet Tracer

Pada Cisco Packet Tracer versi 7.1.1 dilengkapi perangkat pembelajaran Internet of Things yang terdiri dari Komponen Board, Aktuator dan Sensor yang berada pada sisi kanan bawah yang terdapat pada software cisco packet tracer, berikut contoh komponen dalam gambar berikut

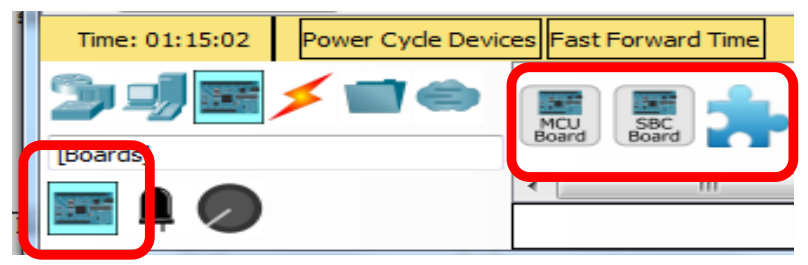

Gambar. 7 Board MCU

Pada Board terdapat MCU Board dan SBC Board dimana board ini merupakan mikrokontroller unit yang dapat diprogram.

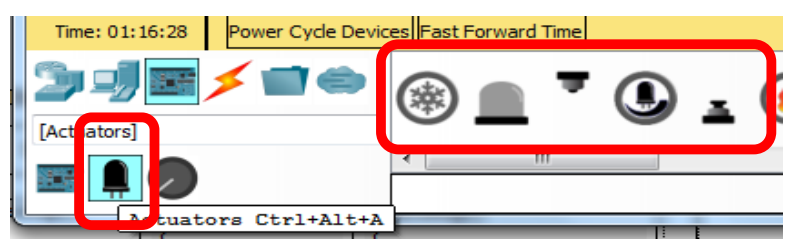

Gambar. 8 Aktuator

Pada Akuator terdapat bagian output seperti Alaram, LCD, Motor Penggerak dan lain-lain.

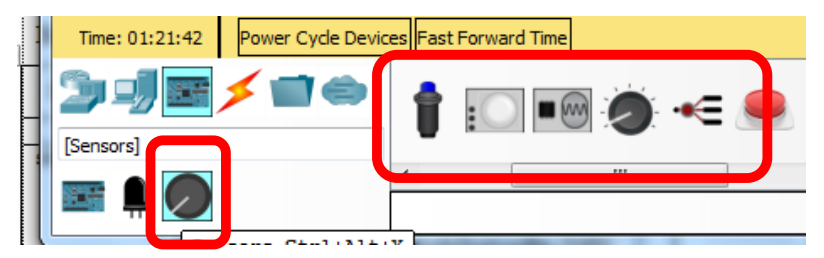

Gambar. 9 Sensor

Pada bagian sensor terdapat bagian input seperti Sensor gerak, Sensor Photo dan lain-lain.
Tabel I

Bahasa Arduino diimplementasikan dalam Packet Tracer

\begin{tabular}{|c|c|c|}
\hline FUNGSI & $\begin{array}{l}\text { PACKET } \\
\text { TRACER }\end{array}$ & ARDUINO \\
\hline \multicolumn{3}{|c|}{ Structure } \\
\hline setup() & $\begin{array}{l}\text { function setup }() \\
\{ \\
\text { pinMode }(0, \text { INPU } \\
\text { T); } \\
\}\end{array}$ & $\begin{array}{l}\text { void setup() } \\
\{ \\
\text { Serial.begin(9600); } \\
\text { pinMode(buttonPin, INPUT); } \\
\}\end{array}$ \\
\hline $\operatorname{loop}()$ & $\begin{array}{l}\text { function } \operatorname{loop}() \\
\{ \\
\text { Serial.println(digital } \\
\text { Read }(0)) ; \\
\}\end{array}$ & $\begin{array}{l}\text { void loop }() \\
\{ \\
\text { if }(\text { digitalRead(buttonPin) }== \\
\text { HIGH) } \\
\text { Serial.write('H'); } \\
\text { else } \\
\text { Serial.write('L'); } \\
\text { delay }(1000) ; \\
\{\end{array}$ \\
\hline \multicolumn{3}{|c|}{ Digital I/O } \\
\hline $\begin{array}{l}\text { pinMode(slot } \\
\text {, mode) }\end{array}$ & $\begin{array}{l}\operatorname{pinMode}(1, \text { OUTPU } \\
\text { T); } \\
\operatorname{pinMode}(2, \text { INPUT }) \text {; }\end{array}$ & 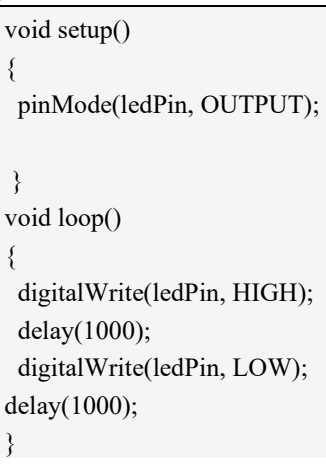 \\
\hline $\begin{array}{l}\text { digitalRead(s } \\
\text { lot) }\end{array}$ & $\begin{array}{c}\text { var val = digitalRead } \\
(1)\end{array}$ & $\begin{array}{l}\text { void loop }() \\
\left\{\begin{array}{l}\text { val = digitalRead(inPin); } \\
\text { digitalWrite(ledPin, val); } \\
\}\end{array}\right.\end{array}$ \\
\hline $\begin{array}{l}\text { digitalWrite( } \\
\text { slot, value) }\end{array}$ & $\begin{array}{c}\text { digitalWrite( } 1, \text { HIG } \\
\mathrm{H})\end{array}$ & $\begin{array}{l}\text { void loop() } \\
\{ \\
\text { digitalWrite(ledPin, HIGH); } \\
\text { delay(1000); } \\
\text { digitalWrite(ledPin, LOW); } \\
\text { delay(1000); } \\
\text { \} }\end{array}$ \\
\hline
\end{tabular}

\section{METODOLOGI}

Perancangan untuk pembelajaran Internet of Things (IoT) ada dua yaitu pertama deteksi gerak dan kedua pintu garasi mobil otomatis, pada bagian pertama yaitu deteksi gerak diperlukan perangkat yaitu Board atau Microcontroller unit (MCU), Aktuator terdiri dari perangkat seperti Speaker, Lampu LED, Alaram, dan bagian Sensor terdiri dari Sensor 
gerak atau motion sensor dimana digunakan untuk mendeteksi gerakan, selanjutnya perangkat penggerak Garasi Mobil yang dihubungkan dengan server dan akan dikendalikan melalui smartphone.

Langkah-langkah perancangan pembelajaran Internet of Things menggunakan software Cisco Packe Tracer 7.1.1 adalah menyiapkan perangkat keras :

\section{A. Board Microcontroller Unit}

Microkontroler unit adalah sebuah chip yang berfungsi sebagai pengontrol rangkaian elektrik dan elektronika, umunya dapat menyimpan program, bagian Board MCU terdapat pada bagian sisi bawah pada software Cisco Packet Tracer dimana perangkat keras ini digunakan sebagai prosesor atau pemroses setiap instruksi atau program yang dikehendaki.

Pada Board MCU terdapat pin digital mulai dari DO, D1, D2, D3, D4 dan seterusnya selain pin Digital ada juga pin Analog mulai dari A0, A1, A2, A3 dan seterusnya pin-pin ini dihubungkan dengan sensor ataupun aktuator

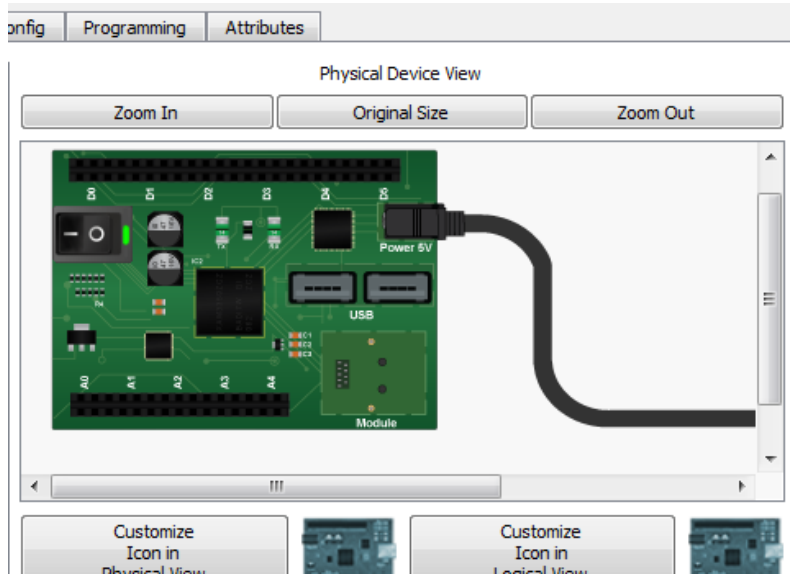

Gambar. $10 \mathrm{MCU}$

\section{B. Sensor}

Sensor adalah alat yang digunakan untuk mendeteksi adanya perubahan lingkungan fisik atau kimia, bagian sensor terdapat pada bagian sisi bawah pada software Cisco Packet Tracer dimana perangkat keras ini digunakan sebagai input.

Pada perangkat sensor ini digunakan yaitu sensor deteksi gerak dimana sensor deteksi gerak ini dihubungkan dengan board MCU pada pin D0

\section{Aktuator}

Aktuator adalah sebuah peralatan mekanis untuk menggerakkan atau mengontrol sebuah mekanik, bagian aktuator terdapat pada bagian sisi bawah pada software Cisco Packet Tracer dimana fungsi bagian Aktuator merupakan perangkat keras yang digunakan sebagai output atau hasil dari proses setiap instruksi atau program yang dibuat.
Pada perangka aktuator ini yang digunakan yaitu Lampu LED, Speaker dan Alaram. perangkat ini dihubungkan dengan Board MCU pada pin D1, D2 dan D5.

\section{Server/Home gateway}

Server atau homegateway merupakan komputer pusat yang digunakan untuk melayani perangkat keras Internet of Things (IoT) yang terhubung pada jaringan. Pada server dikonfigurasi DHCP Server sehingga perangkat yang terhubung dengan server akan mendapatkan IP Addres secara otomatis dan DNS Server

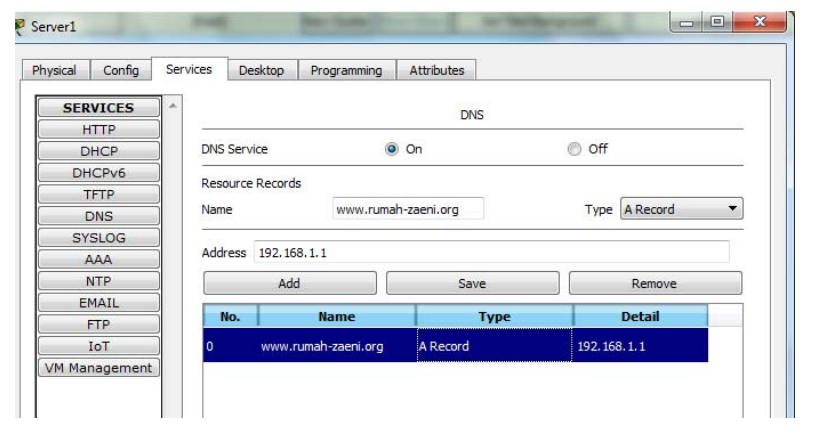

Gambar. 11 Layanan Server

\section{E. Access Point (Wifi)}

Acces Point merupakan perangkat keras yang digunakan untuk menghubungkan perangkat smartphone, Tablet-PC, Laptop dengan server melalui gelombang radio.

Pada metode perancangan ini perangkat yang digunakan diantaranya Board MCU, Alaram, Sensor gerak, Speaker dan Lampu LED, cara kerja pada teknologi IoT yang pertama yaitu mendeteksi setiap ada objek bergerak yaitu jika sensor gerak mendeteksi adanya gerakan maka alaram, speaker serta lampu LED sebagan lampu indikator akan menyala.

Pengendali pintu garasi mobil yang dikendalikan melalui perangkat smartphone atau tablet-pc dibutuhkan perangkat Komputer server dengan diberi IP Address = 192.168.1.1 dengan nama domain $=$ www.rumah-zaeni.org dan sekaligus sebagai gateway pada jaringan internet,

Cara kerja teknologi IoT ini yaitu Smartphone atau tabletPc mengakses halaman server web dengan Url : www.rumahzaeni.org setelah itu akan tampil pada halaman yaitu user login, setelah user dapat login maka dapat membuka dan menutup pintu garasi mobil

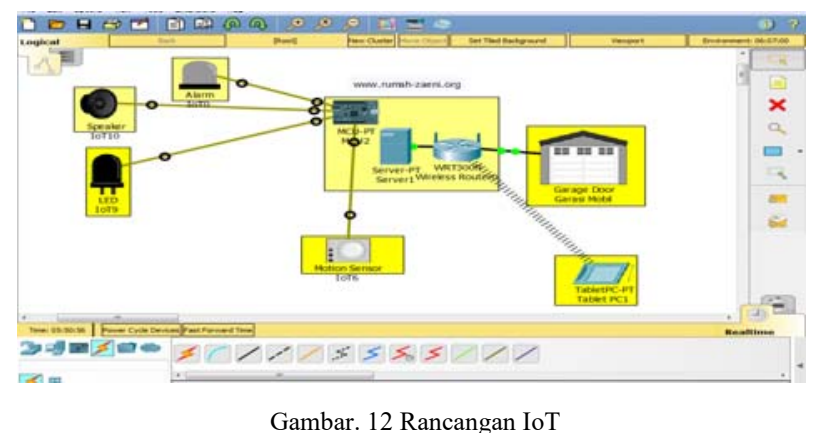

Gambar. 12 Rancangan IoT 


\section{HASIL DAN PEMBAHASAN}

Simulasi Pembelajaran Internet of Things menggunakan Cisco Packet Tracer menjadikan pembelajaran akan lebih aman bagi siswa, Fitur dalam simulasi pembelajaran adalah sebagai berikut :

> Pengenalan Pengenalan Area Kerja Cisco Packet Tracer

$>$ Perancangan dan Implementasi Internet of Things (IoT) untuk deteksi gerak dan kendali garasi mobil melalui smartphone.

\section{A. Pengenalan Area Kerja Cisco Packet Tracer}

Pada pembelajaran ini dikenalkan fitur yang tersedia pada software cisco paket tracer yang digunakan dalam merancang teknologi Internet of Things mulai mengenal area kerja, menambahkan perangkat ke area kerja, pengaturan sampai pada pengujian, sehingga siswa terus dapat bereksperimen untuk merancang teknologi Internet of Things.

\section{B. Perancangan dan Implementasi Internet of Things (IoT)} untuk deteksi gerak dan kendali garasi mobil melalui smartphone

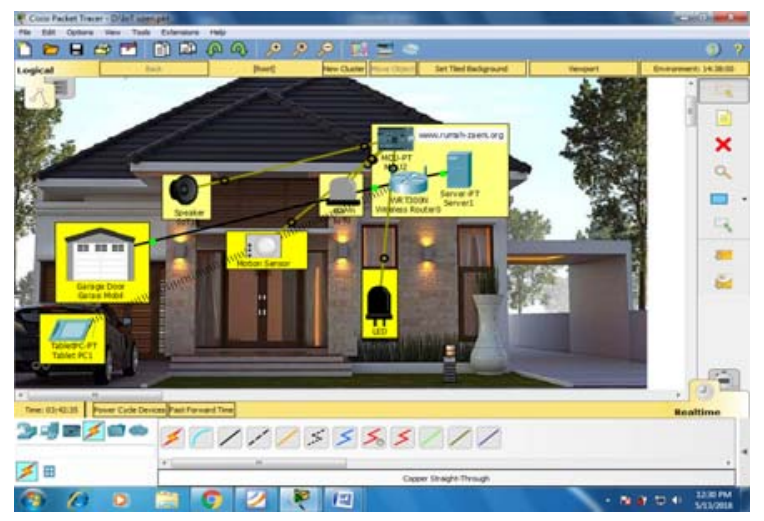

Gambar. 13 Implementasi IoT

Untuk penerapan deteksi gerak maka diperlukan program yang dimasukan kedalam perangkat Board Mikrokontroller unit (MCU), pilih board MCU lalu dibuka kemudian pilih programming kemudian pilih Blink (JavaScript) dan pilih main.js dan pada bagian sisi kanan, selanjutnya dapat diberikan perintah program seperti gambar.

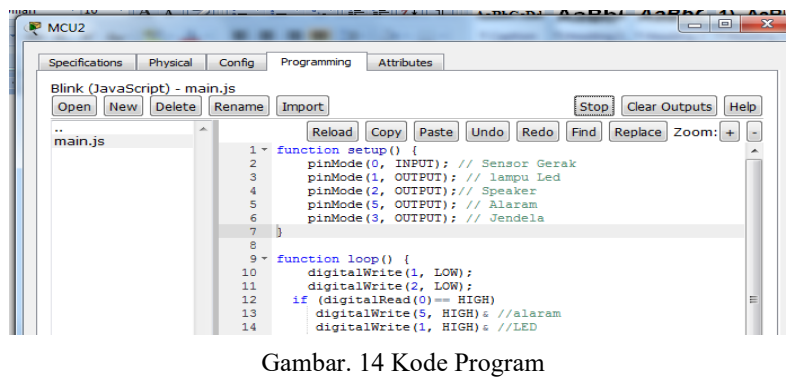

Kode program lengkapnya sebagai berikut :

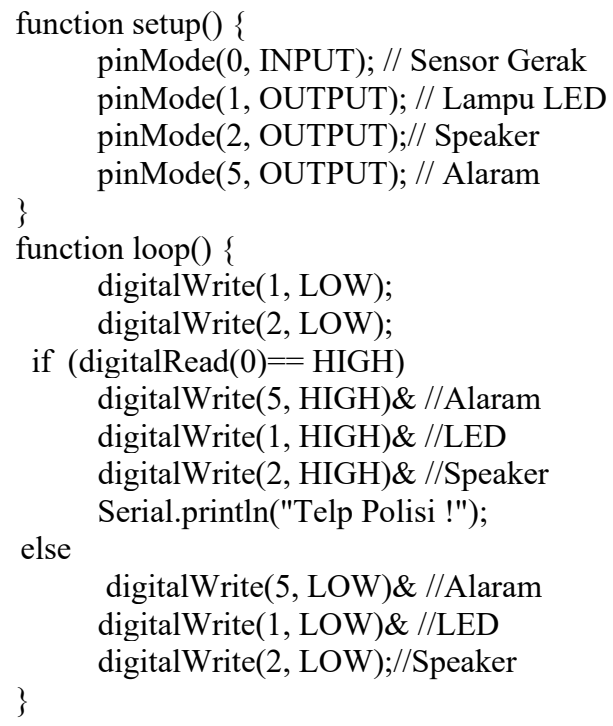

Keerangan Perintah diatas adalah digitalRead(0) adalah perintah sebagai inputan yang dihubungkan dari Sensor gerak ke pin D0, digitalWrite(1) adalah perintah sebagai output yang dihubungkan ke Lampu LED dari pin D1, digitalWrite(2) adalah perintah sebagai output yang dihubungkan ke Speaker dari pin D2, digitalWrite(5) adalah perintah sebagai output yang dihubungkan ke Alaram dari pin D5.

Setelah program diatas dibuat lalu dijalankan, kemudian pada area kerja Cisco Packet Tracer tombol alt ditekan dan mouse diarahkan ke sensor gerak, maka alaram, speaker dan lampu LED menyala seperti pada gambar

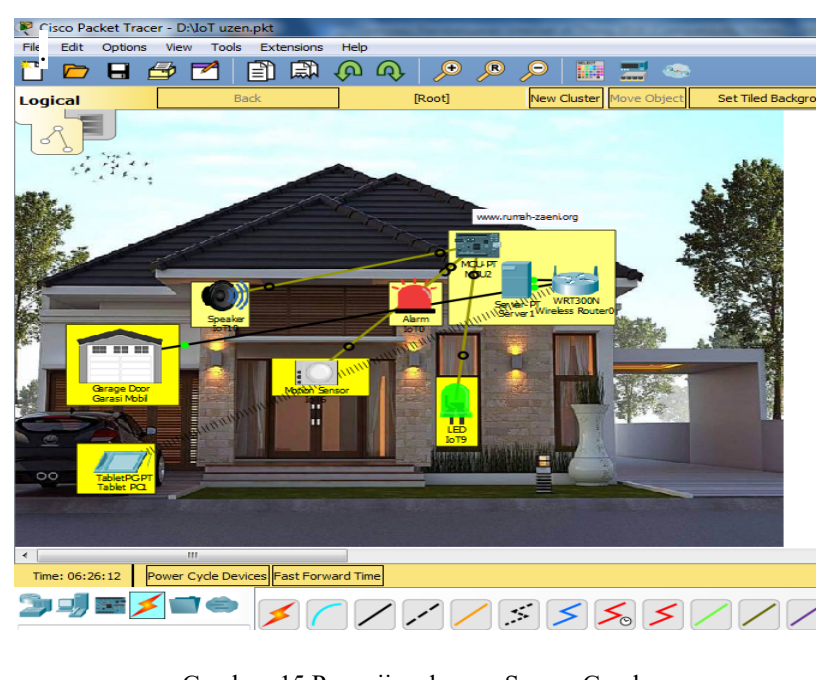

Gambar. 15 Pengujian dengan Sensor Gerak

Untuk membuka pintu garasi mobil dapat menggunakan perangkat semartphone atau tablet-PC dengan cara mengakses server web pada sebuah jaringan, perangkat pintu garasi mobil terhubung dengan server, pada server dihubungkan dengan 
access point agar Smartphone atau Tablet-PC dapat terhubung melalui jaringan wirelss. berikut contoh tampilan dari smartphone atau tablet PC, pada halaman login diberikan username dan password yaitu admin

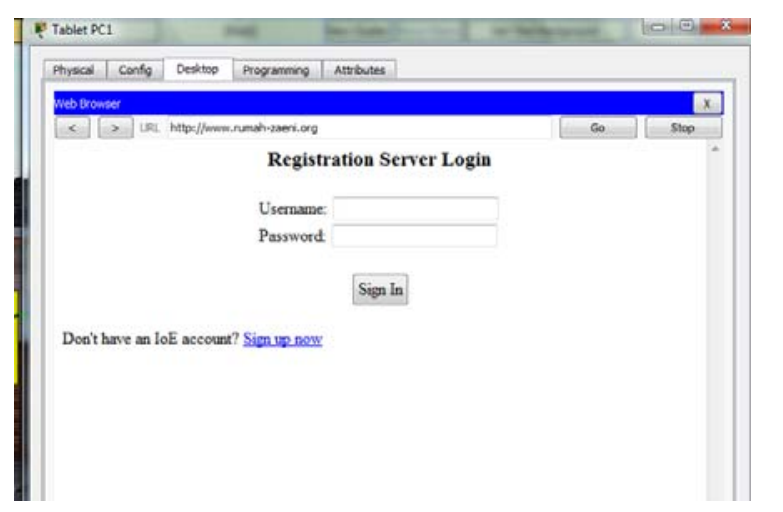

Gambar. 16 Halaman Login

Setelah diberikan username dan password maka akan tampil pada jendela browser nama perangat yaitu garasi mobil yang terhubung melalui jaringan yang dapat digunakan untuk membuka dan menutup pintu garasi. Pada halaman browser tampil Garasi Mobil sedang On yaitu pintu garasi sedang tertutup, jika ingin membuka pintu garasi dapat dilakukan dengan menekan tombol hijau pada Garage Door.

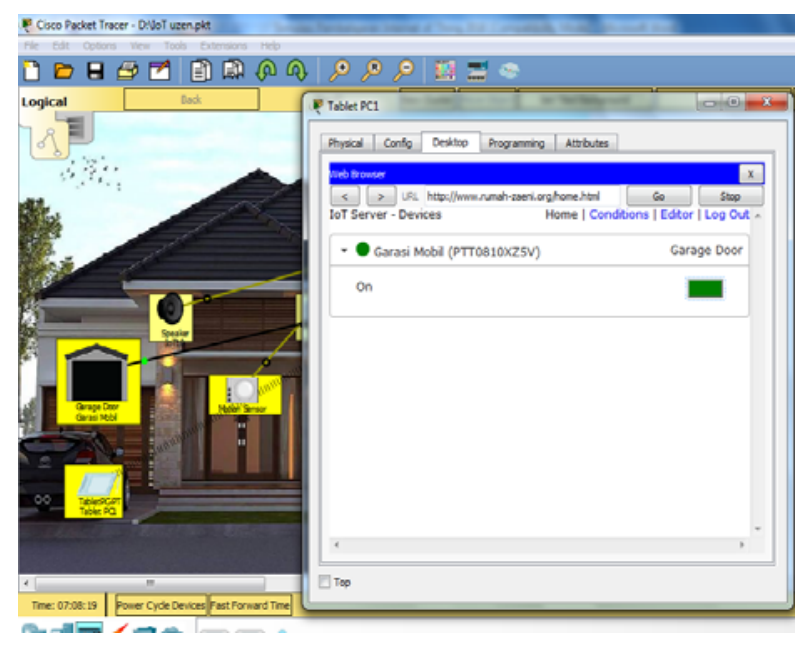

Gambar. 17 Pengujian dengan Smartphone atau Tablet

\section{SIMPULAN}

Keterbatasan dan ketersediaan perangkat keras Untuk pembelajaran Internet of Thinks ternyata dapat diatasi dengan menggunakan perangkat simulasi yaitu Cisco Packet Tracer, tanpa harus membeli perangkat yang begitu mahal walaupun cara ini tidak dapat mewakili $100 \%$ seperti pada dunia nyata akan tetapi secara prinsip keilmuan dapat dipertanggung jawabkan menggunakan software Cisco Packet Tracer.

Sensor deteksi dapat bekerja secara sempurna ketika ada objek yang bergerak melintasi sensor sehingga Alaram, Speaker dan Lampu LED sebagai indikator dapat menyala.

Smartphone atau Tablet-PC yang terhubung melalui Access Point dan terhubung dengan PC-Server sehingga Smartphone atau tablet-PC dapat membuka dan menutup pintu garasi.

\section{REFERENSI}

[1] https://www.netacad.com/courses/iot/

[2] https://www.cisco.com/c/dam/en us/about/ac79/docs/innov/IoT IBSG 0411FINAL.pdf

[3] Mufadhol, Simulasi Jaringan Komputer dengan Menggunakan Cisco Packet Tracer, Jurnal Nasional, -, 07 Juni 2012

[4] Miftah Z., Analisis Peningkatan Kinerja Lan Dengan Routing Dinamis Berbasis OSPF Single Area Dan Intervlan Menggunakan Cisco Packet Tracer 7.1. Jurnal Esit. Vol. 9 No.2.

[5] GH Cahyono, internet of things (sejarah,teknologi dan penerapannya) Jurnal Forum Teknologi, Vol. 06 No. 3.

[6] Sofana, Iwan. (2010). CISCO CCNA \& Jaringan Komputer. Bandung: Informatika. 